\title{
Chapter 9 \\ Bio-ethical Considerations for Public Health in Humanitarian Action
}

\author{
Siri Tellier
}

\begin{abstract}
The objectives and operational norms of public health are explicitly and strongly based on bio-ethical principles, involving many dilemmas. To a great extent, these principles remain the same when dealing with public health in humanitarian action (PHHA), but their application may involve even more excruciatingly difficult decisions and dilemmas. This chapter reflects on what those principles and dilemmas are, and how they have changed over time. It describes how the global health situation has changed dramatically over the last decades, and what implications that has for health in emergency situations. It also addresses the changing nature of disasters, including more protracted emergencies involving long term displacement, fragile contexts as well as the effect on the capacity of health systems as they are under increasing pressure and attack. Finally, it notes some of the major improvements in humanitarian response, including development of widely accepted guidelines and coordination mechanisms, and how this has contributed to improvements in saving lives and preventing morbidity.
\end{abstract}

Keywords Public health disaster · Health risk reduction - Displacement - Fragile contexts

\subsection{Introduction}

The objectives and operational norms of public health are explicitly and strongly based on bio-ethical principles, involving many dilemmas. To a great extent, these principles remain the same when dealing with public health in humanitarian action (PHHA), but their application may involve even more excruciatingly difficult decisions and dilemmas.

\footnotetext{
S. Tellier $(\bowtie)$

Health in Emergencies and Refugee Health, School of Global Health, University of Copenhagen, Copenhagen, Denmark

e-mail: stellier@sund.ku.dk 
To support these statements, and to point to some of the most acute bio-ethical dilemmas, we will build upon a review of changes over the last two centuries, in particular:

1. What is a public health disaster?

2. What is the overall objective of PHHA?

3. How has the global health situation changed?

4. How have those changes influenced the health impact of disasters?

5. How has the global approach to public health changed?

6. How has that influenced the approach to PHHA?

The final section explores

7. Personal reflections: some bio-ethical challenges and dilemmas.

PHHA is an action-oriented field. Therefore, both theoretical concepts and operational norms will be discussed.

\subsection{What Is a Public Health Disaster?}

The United Nations Office for Disaster Risk Reduction (UNISDR) has defined a disaster as 'A serious disruption of the functioning of a community or a society at any scale due to hazardous events interacting with conditions of exposure, vulnerability and capacity, leading to one or more of the following: human, material, economic and environmental losses and impacts', with the annotation that this may test or exceed the capacity of the affected society to cope with its own resources, and require external assistance (UNISDR 2016). In the following, we will use that as a working definition.

The Centre for Research on the Epidemiology of Disasters (CRED), which maintains one of the most widely used databases on disasters, records an event as a 'disaster' if it conforms to at least one of the following criteria:

- Ten or more people dead

- One hundred or more people affected

- The declaration of a state of emergency

- A call for international assistance (CRED)

There are many definitions of a public health disaster. However, most of them base themselves on the concept that a hazard has caused 'excess mortality', that is, additional deaths above the 'baseline', pre-disaster level.

In 1990 Toole and Waldman proposed that 'excess mortality' be seen as a defining characteristic for identifying a state of emergency. To arrive at a quantitative metric, they proposed that a doubling of the baseline mortality should be considered as the threshold value. They took that baseline to be the average mortality for developing countries as a whole in 1990, arriving at a threshold crude mortality rate of 1 death per 10,000 population per day. This threshold was supplemented by a specific 
metric for children aged under 5 years of age, since that population is most at risk for excess mortality ${ }^{1}$ (Sphere Project 2004; Toole and Waldman 1990).

Measures of mortality are often supplemented by a quantitative measure of malnutrition in children aged under 5 years, which is seen as a proxy for the overall health of the population. Usually the threshold level for classifying a situation as a serious emergency is that the prevalence of global acute malnutrition ${ }^{2}$ in children aged 6-59 months is above 10\% (UNHCR 2018).

Another term has been added more recently: a 'Public Health Emergency of International Concern' (with the somewhat unfortunate abbreviation 'PHEIC'). The 2005 WHO International Health Regulations (IHR) define a PHEIC as

an extraordinary event which is determined:

- to constitute a public health risk to other States through the international spread of disease; and

- to potentially require a coordinated international response. (WHO 2008 p9)

Notably, the IHR are legally binding - that is, all States are obliged to report to WHO on health events (both communicable disease but also for example radiation), and represent a major strengthening of the reporting system (Baker and Fidler 2006). The IHR provides a framework for on-going, early warning surveillance - a cornerstone of public health. It involves on-going analysis to determine whether any given report may be considered to be irrelevant noise, or worrying enough to follow closely, or sufficiently extraordinary to warrant being classified as a PHEIC. This thinking is not unique. Many countries have a system for reporting disease on a regular (e.g. weekly) basis. The DEWS (Disease Early Warning System which tracks communicable disease), GLEWS (Global Early Warning System which tracks animal-ecosystem-human health interactions) or FEWS (Food Early Warning System) point to the significance attached to identifying potential emergencies.

That is, from a public health point of view, but arguably also from the wider humanitarian action point of view, disasters are conceptualised in terms of the level of excess mortality they cause, and humanitarian action in general is judged in terms of how well it succeeds in saving lives.

Finally, 'public health' is defined as 'all organized measures (whether public or private) to prevent disease, promote health and prolong life among the population as a whole' (WHO Glossary, p3). This definition includes both modifiable environmental or individual determinants of health (preventive measures) as well as essential health services (treatment and care measures) (Koplan et al. 2009).

This is not to say that morbidity is absent from humanitarian mind-sets. However, it has taken time to achieve prominence, both in humanitarian and other situations (see the discussion on DALYs below).

\footnotetext{
${ }^{1}$ Mortality exceeding 1 death per 10,000 population per day, or 2 children aged $0-4$ per 10,000 children aged 0-4 per day. In 1990, that threshold represented a doubling of the baseline mortality for developing countries.

${ }^{2}$ Global Acute Malnutrition (GAM) is calculated with the Z-score defined as a weight-for-height index less than -2 standard deviations from the mean weight of a reference population of children of the same height and/or having oedema.
} 


\subsection{What Is the Overall Objective of PHHA?}

A significant milestone in humanitarian action was the creation of the International Committee of the Red Cross in 1863. A central objective of that organisation was to provide health care to wounded soldiers, and to create the humanitarian space for health workers to be able to do so. That is, as mentioned above, from the beginning of humanitarian action, 'saving lives' was one of its central objectives and ethical mandate.

Bringing mortality down to the 'baseline', pre-disaster level remains a key objective, not only for health workers, but for all humanitarian response. The 2011 Sphere Handbook, which represents widely used standards for humanitarian action, states that 'saving lives with dignity' is a central purpose for all humanitarian action, and notes that the standards are 'a set of minimum standards in key life-saving sectors ... water supply, sanitation and hygiene promotion; food security and nutrition; shelter, settlement and non-food items; and health action' (Sphere Project 2011, p. 4).

\subsection{How Have the Baseline Health Problems Changed?}

One of the most central bio-ethical approaches of public health is that it must prioritise action in order to address the most important public health problems. Therefore, it is essential to establish what those health problems are.

Those problems have changed over time. The health impact of disasters is highly dependent on the baseline health situation of the affected population before disaster struck. Therefore, in the following we will list important characteristics of that baseline global health situation and recent trends.

\subsubsection{The Baseline: Global Life Expectancy Has Increased Dramatically}

In the year 1800, global life expectancy was estimated at around 28.5 years (Riley 2005). With industrialisation, it began to improve. By $1950^{3}$ the global average had reached 47 years (United Nations 2017). By 2017 the estimated average global life expectancy was 72 years, that is, an increase of more than 4 months per year since 1950, with no upper limit in sight (Christensen et al. 2009; United Nations 2017) (Table 9.1).

\footnotetext{
${ }^{3}$ The estimates are given for a 5-year period, e.g. 1950-1955, but are listed here for single years for easier reading, e.g. 1950.
} 
Table 9.1 Life expectancy in high, middle and low income countries (HMLICs, 1950-1955 and 2015-2020 United Nations 2017)

\begin{tabular}{l|l|l|l}
\hline & $1950-1955$ & $2015-2020$ & Increase \\
\hline World & 47 & 72 & 25 \\
\hline HIC & 65 & 81 & 16 \\
\hline MIC & 43 & 71 & 28 \\
\hline LIC & 35 & 63 & 28 \\
\hline
\end{tabular}

Table 9.2 Burden of disease, different types of disease, 1990 and 2015 (Global Burden of Disease Study 2013 Collaborators 2015)

\begin{tabular}{l|l|c|c}
\hline & Types of disease & 1990 & 2015 \\
\hline $\begin{array}{l}\text { Group } \\
1\end{array}$ & Communicable diseases, nutritional, maternal and perinatal conditions & $34 \%$ & $20 \%$ \\
\hline $\begin{array}{l}\text { Group } \\
2\end{array}$ & $\begin{array}{l}\text { Non-communicable diseases (including cancer, heart disease, diabetes, } \\
\text { chronic lung disease) }\end{array}$ & $57 \%$ & $70 \%$ \\
\hline $\begin{array}{l}\text { Group } \\
3\end{array}$ & $\begin{array}{l}\text { Injury (including suicide, homicide, mass violence, accidents, force of } \\
\text { nature) }\end{array}$ & $9 \%$ & $10 \%$ \\
\hline
\end{tabular}

\subsubsection{Disparity Between Countries Has Narrowed, But Some Still Lag}

Life expectancy in High Income Countries increased by 16 years in the period 1950-2015. In Low and Middle Income Countries the increase was 28 years. Thus, the gap narrowed. However, so-called fragile states and contexts saw less progress than the average (World Bank).

\subsubsection{The Causes of Death Have Also Changed over This Period}

Historically, the top causes of deaths were communicable diseases and starvation. However, already by 1990 we had become better at controlling those diseases (called 'Group 1' in the table above) (Table 9.2).

Today, Group 1 causes only $20 \%$ of deaths. The proportion of deaths attributed to non-communicable diseases (Group 2 above) has increased from 57\% to $70 \%$ This shift is referred to as the 'epidemiologic transition' (Omran 1971). 
Table 9.3 Demographic shifts, 1950-2015, Japan, Somalia and the World (United Nations 2017)

\begin{tabular}{l|l|l|l|l|l|l}
\hline & \multicolumn{3}{l}{ Japan } & Somalia & \multicolumn{2}{l}{ World } \\
\cline { 2 - 8 } & $1950-5$ & $2015-20$ & $1950-5$ & $2015-20$ & $1950-5$ & $2015-20$ \\
\hline Crude birth rate (births/1000/year) & 23.6 & 8.1 & 48.9 & 42.9 & 36.9 & 18.6 \\
\hline Total fertility (births/woman) & 3.0 & 1.5 & 7.3 & 6.1 & 5 & 2.5 \\
\hline Crude death rate (deaths/1000/year & 9.1 & 10.8 & 29.8 & 11.0 & 19.1 & 7.7 \\
\hline Life expectancy & 63 & 84 & 34 & 57 & 47 & 72 \\
\hline \% of population aged 0-4 & 14 & 4 & 17 & 18 & 13 & 9 \\
\hline \% of population aged 65+ & 5 & 28 & 3 & 3 & 5 & 9 \\
\hline
\end{tabular}

\subsubsection{The Age Group Experiencing Most Improvement Is Children Under 5}

In 1950, at the global level $21.5 \%$ of children died before they reached the age of 5 . In 2017 it was $4.3 \%$ (United Nations 2017). Young children are the ones most vulnerable to Group 1 diseases, and they have benefited the most from improvements.

\subsubsection{The Demographic Transition Has Accentuated Shifts in Health}

The 'demographic transition' occurs as countries move from the high death and birth rates common around 1800 . Often, declines in mortality, in particular under-5 mortality, are followed a few decades later by declines in birth rates. The result is temporary rapid population growth and long term ageing of the population.

Thus, in a country such as Somalia, which is in the early stages of both the epidemiologic and demographic transitions, children under 5 constitute $21 \%$ of the population, whereas in Japan, which began the transition around 1950, the proportion is around $4 \%$ (Table 9.3).

The two transitions, demographic and epidemiologic, interact with each other. Thus Somalia, with a high proportion of young children, has a higher burden of group 1 diseases, whereas in Japan, with an older population, most deaths are attributed to Group 2 diseases.

\subsubsection{Urbanization Also Has Significant Health Implications}

In $1950,30 \%$ of world population resided in urban areas, while by 2008 it was more than half (UN 2014). An increasing number is living in low elevation coastal zones (LECZ), vulnerable to inundation, and the number living in slums remains close to a billion (UN 2015). Urban living provides potential for improvements in health, but 
also for increased risk factors: poor water, sanitation and hygiene (WASH), crowding, less access to healthy food, unhealthy life styles, and violence/dangerous traffic/job conditions. This may cause a 'triple burden of disease' from the three above-mentioned disease groups.

\subsubsection{A New Metric: Beyond Mortality to Healthy Life Years}

As indicated above, the health of populations is often measured in terms of mortality. The 'global burden of disease study' (GBD), first published in 1994 (Murray et al. 1994) introduced a metric to measure morbidity: the Disability Adjusted Life Years (DALY). This measures not only how many years people live, but how many years they live in good health. The metric was introduced partially because, with a growing burden of chronic Group 2 diseases, growing numbers of people were living with chronic disabilities. It was a milestone in the conceptualization of health, partially because it drew attention to the burden of disease due to mental illness, which rarely causes death, but causes much ill health.

\subsection{How Have Those Changes Influenced the Health Impact of Disasters?}

\subsubsection{Mortality Due to Disasters Is Now Relatively Modest}

Globally, there are 55-60 million deaths annually (United Nations 2017). At present, only a small proportion of that number is a result of disasters.

This was not always so. With respect to armed conflict, tens of millions died in the two world wars of the twentieth century. The 1994 Rwanda crisis is estimated to have resulted in over half a million deaths (Global Burden of Disease 2015 Mortality and Causes of Death Collaborators 2016). Data on deaths due to violence in Iraq are hotly contested, but most estimates are in the range of a few hundred thousand over several years (Burnham et al. 2006; Tapp et al. 2008). The same holds for Syria (Price et al. 2014). On average, deaths to collective violence average 200,000300,000 per annum.

For natural disasters, outbreaks of epidemics or starvation historically caused dramatic spikes in mortality. Starvation in Ireland killed about an eighth of the population in the middle of the nineteenth century (Ó Gráda 2009). The global influenza epidemic of 1918 killed more people than the First World War ( 1 estimate is 50 million) (Taubenberger and Morens 2006). In recent decades, the average annual number of deaths due to natural disasters is around 100,000, and whereas malnutrition seems to be on the rise since 2016, mass starvation is rare. 
Individual populations can experience overwhelming impact, for example male life expectancy in Syria is estimated to have dropped from 73.9 to 62.6 since 2010 (Global Burden of Disease 2015 Mortality and Causes of Death Collaborators 2016). However, this is still less than the 20-year drop in life expectancy in some sub-Saharan countries due to AIDS (United Nations 2017).

Thus, in general, the proportion of deaths which are due to disasters is lower than was historically the case, and other causes of death are more prominent. However, even though a high-profile epidemic like Ebola caused 'only' around 11,000 deaths, it caused great international havoc (duBois et al. 2015).

\subsubsection{The Causes of Death in Disasters Have Followed the Epidemiologic Transition}

In parallel, the causes of death in disasters have also changed over time. Over the course of the twentieth century it became clear that, although combatants were at special risk for Group 3 diseases (injury), civilian populations, especially those forcibly displaced, were at risk for Group 1 diseases. That is, although the epidemiologic transition meant better control of communicable diseases, when the preconditions for good health disappeared, for example WASH, nutrition and shelter, the epidemiologic transition was reversed. In particular, young children, who are the most vulnerable to Group 1 diseases, were at great risk for excess mortality.

Gradually, awareness has grown that natural disasters (e.g. hurricanes) do not necessarily result in outbreaks of communicable diseases if the health system is more or less intact and 'herd immunity' is high (that is, a high proportion of the population is immune, for example because they have been vaccinated) (Sphere Project 2011). Thus, the Kobe earthquake in Japan did not cause major outbreak of communicable disease; neither did the 2004 Indian Ocean tsunami in the affected countries.

Attention to mental health had already begun to increase in the 1990s, as awareness of chronic conditions and disabilities increased. However, until recently other Group 2 diseases, that is NCDs such as diabetes or heart disease, received little attention (Demaio et al. 2013). This changed with the Syrian crisis. The baseline population in Syria before the crisis was older, more urbanised and more affluent than the affected populations in most of the crises of the previous two decades. They had very high levels of some of the risk factors for NCDs, such as obesity, but had survived due to good health care. As half the Syrian population is displaced, it has become a challenge to provide people living with chronic NCDs with continuous, expensive treatment (Rabkin et al. 2016; Ruby et al. 2015).

In general, disasters have a different impact on different population groups, which is an essential realisation for public health prevention and care.

As mentioned above, young children are at special risk for Group 1 diseases. Older people are sometimes at special risk: $71 \%$ of those who died in the wake of 
Hurricane Katrina in 2005 were 60 years and older (Adams et al. 2011). Women tend to be at somewhat higher risk in natural disasters, whereas men are generally more at risk in many conflict related settings (Eklund and Tellier 2012; Tellier 2014). Displaced persons, in particular those who are internally displaced (IDPs), are at particular risk, as their usual means of preventing disease (food, WASH, shelter) are disrupted (CRED 2013; Spiegel et al. 2010).

\subsection{How Has the Baseline Approach to Public Health Changed?}

\subsubsection{Some Milestones in Conceptualisation and Bio-ethical Standards in Public Health}

The thought that health was not only an individual issue between doctor and client, but a bio-ethical issue where society or the State could, and should, intervene, took time to develop, with what might be called a 'big bang' around 1850.

The industrialization of the nineteenth century saw significant societal changes in Europe and North America. Trade was globalising, and travel accelerating with steamships, railroads and building of the Suez Canal. Populations were urbanising, and exposed to crowding and other health risks (Ersoy et al. 2011; Howard-Jones 1975). Seeing these developments, the German physician Rudolph Virchow in a seminal article in 1848 proposed that the medical profession had a special obligation to be the advocates for the poor, but also that health was an interdisciplinary issue, in particular requiring political will including to reduce risk factors (e.g. sanitation) (Virchow 1848).

The societal changes brought successive cholera pandemics - early examples of what would now be called 'Public health emergencies of international concern'. This resulted in what was arguably the first global health initiative: the Sanitary Conference in Paris in 1851. The conference was unsuccessful, as agreement could not be reached on what caused cholera, and therefore what the solution should be (Ersoy et al. 2011; Howard-Jones 1975). Fourteen such conferences were held between 1851 and 1936.

A better understanding came in 1854. John Snow in London mapped who died during a cholera epidemic, from where they drew their water, and when they died (Brody et al. 2000). He used these empirical epidemiological tools to identify a polluted water source as the risk factor, and to mobilise political will to prevent its use. Robert Koch's microscopic isolation of the bacterium causing cholera in 1884 identified the bio-medical cause of the disease. Together, these discoveries contributed to improvements in WASH in many European cities, and major improvements in population health, even before the advent of medical approaches to prevention and treatment, for example vaccination or antibiotics (McKeown and Brown 1955). 
The establishment of the United Nations brought a recognition of health as a human right, therefore underlining the ethical principle of equality, in the WHO Constitution (WHO 1946) and the Universal Declaration of Human Rights (UN 1948). In 1966 a review of the Covenant on Economic, Social and Cultural Rights helped identify health risk factors and the obligation of States to act to improve population health (UN 2000).

The decades of the 1950s-1970s brought a milestone - the eradication of smallpox. An essential precondition for that success was the strategy: 'surveillance and containment'. This entailed targeted vaccination of those who might have come into contact with infected individuals, so that only a few per cent of a population needed to be vaccinated, rather than trying to reach everyone, saving both money and health system capacity (Fenner 1988; Foege et al. 1975).

In 1978 the Alma Ata conference on primary health care set a goal of 'Health for All by 2000', therefore further operationalising the bio-ethical value of equal access to basic health care (WHO 1978). It also made explicit the idea that the preconditions for health go beyond the health sector, including community participation and education.

However, the financial crisis of the 1980s resulted in 'structural adjustment'. In that optic, public health was seen as an expensive, non-essential consumer good. This resulted in 'selective primary health care', focusing on inexpensive targeted interventions, for example immunization of children (Cash et al. 1987).

The 1993 World Bank report 'investing in health' brought back the idea of health as an investment which was a necessary precondition for development (World Bank 1993). It was a further significant shift when the Commission on Macro-economics and health in 2001 elaborated on this, identifying a low level of cost (30-40 USD per year) for a basic health package, thus maintaining the thought that cost must be contained, but also going beyond the narrow targeted approach (WHO 2001).

Inherent in this history is the on-going dispute about the respective benefits of so-called 'vertical' versus 'horizontal' approaches. The vertical approach targets a particular disease, whereas the horizontal focuses on how to build up health systems which can respond to any health hazard and improve overall wellbeing.

The Millennium Development Goals (MDGs), launched in 2001, had a primarily vertical approach on health, addressing individual diseases such as HIV/AIDS. There has been much progress on the MDG health targets since 2000 (UN 2015). However, health systems were not prioritized.

In 2007 WHO launched a description of what is called the ' 6 building blocks of health systems' (WHO 2007):

1. Leadership and Governance

2. Service delivery

3. Health information

4. Human Resources

5. Medicines and Technologies

6. Financing 
These building blocks are now widely used as conceptual framework. The Sustainable Development Goals (SDGs), launched in 2015, take an explicitly horizontal approach, both in the health goals ('wellbeing throughout the life cycle') and the proposed solutions, including Universal Health Coverage (UHC), defined as: 'all people obtain the health services they need without suffering financial hardship to pay for them, a well-run health system, a system for financing, access to essential medicines and technologies, and well trained health workers' (WHO 2014).

The reader may be struck by the constant referrals to WHO standards, but as will be explained below, they form the basis for widely accepted PHHA guidelines.

The above history has helped develop some key characteristics of Public health, which are also central in PHHA (Koplan et al. 2009):

- Population rather than individual focus

- Evidence based - epidemiology and surveillance as cornerstones of public health - the ethical obligation to seek scientifically founded solutions

- Equality (a human rights approach)

- Reducing modifiable risk factors - prevention as well as health care, and therefore an inter-sectoral approach and responsibility

- Efficiency and prioritization - prioritising the most serious health issues, developing and adjusting strategy to get the biggest 'bang for the buck'

These characteristics and bio-ethical norms become particularly relevant for humanitarian action, where there may be overwhelming health issues, where basic preconditions for survival and health systems may have been destroyed, and where there is a risk of sometimes deliberate exclusion of vulnerable groups from health care.

\subsection{How Has That Influenced the Approach to PHHA?}

\subsubsection{The Evidence Base: Surveillance and Assessment}

As mentioned above, surveillance and epidemiological data are cornerstones of public health.

In a disaster, this is even more crucial. There are several reasons for this, including:

- Guiding the response (assessing the problem, and the evolving effectiveness of the response strategy)

- Reporting to the outside world (gaining political and financial support)

- Underpinning the bio-ethical principles of impartiality and human rights (some groups may need assistance more than others. However, what is seen as responding to need by one actor may be seen as political favouritism by another. Assessment can help establish needs, in a manner perceived to be as objective as possible). 
There are many guidelines for such assessments. They recommend undertaking assessments as a priority, before action is decided, and coordinating among actors (MSF 1997; Sphere Project 2011). A key recommendation is to collect data in a prioritised, phased and pragmatic manner: using rules of thumb, accessing available secondary data to establish the baseline situation, and following up with whatever primary data can be conveniently gathered. Individually, these data may not be representative, but when the information is triangulated (compared among different sources) they can still give a useful picture. Clear, simple case definitions used for screening (e.g. 'have you seen cases of acute, watery diarrhea?') can be useful to involve a wide range of actors, including local populations, in surveillance (Parham 2016; Tellier 2014). Only longer term should large-scale studies collecting high quality primary data be undertaken (Tellier and Roche 2017).

As the Non-Governmental Organisation (NGO) Assessment Capacities Project (ACAPS) suggests:

- know what you need to know

- better to be approximately right than precisely wrong

- make sense not data. (Tellier 2014)

Or, as Gilbert Burnham from Johns University told the author in a personal communication: 'public health is about making decisions on incomplete information'. The bio-ethical imperative is to act (since not doing so might lead to death and suffering) in a timely, impartial and effective manner, but also to learn from mistakes, with accountability to supporters and affected populations. Assessments are essential for this.

Despite the many guidelines, this remains an area with many issues.

Technically, primary data collection can be difficult, time consuming, expensive and dangerous, both for researchers and beneficiary populations. For example, asking women about sexual violence can lead to their being socially ostracised (Sriram et al. 2009).

Reviews of humanitarian response repeatedly show a lack of coordination amongst different humanitarian actors, with each collecting their own data, and using methods and metrics which are not comparable. Data on injuries in Haiti used divergent definitions, making assessment difficult (PAHO 2011).

The reasons for this multiplicity of surveys are speculative. Beyond the technical difficulties, the usual coordination difficulties may come into play. Competition may also be a factor, particularly if donors have the impression that organisations with the most impressive data are the most worthy of financial support (Knox and Campbell 2015; Tellier and Roche 2017). A review by Active Learning Network for Accountability and Performance in Humanitarian Action (ALNAP) found that many field staff of humanitarian organisations had the impression that data were produced for headquarters' advocacy and fund-raising work, rather than operational field activities (Knox and Campbell 2015). 


\subsubsection{Risk Reduction and Prevention}

PHHA is to a great extent concerned with modifiable risk factors, both environmental and individual. As mentioned above, improvements in WASH as well as nutrition have historically had great influence on mortality. This is explicitly indicated in guidelines for PHHA, including those of Médecins sans Frontières (MSF) (1997), Johns Hopkins/International Federation of Red Cross (IFRC)/Red Crescent Societies (Johns Hopkins and IFRC 2007) or the Sphere project (2011). The thought that the risk of excess deaths is not inevitable, but rather a function of several modifiable factors is sometimes expressed as a 'risk equation'. Here, we will use the one introduced by Boudreau and modified by Johns Hopkins/IFRC:

$$
\mathrm{R}=\mathrm{H} \times \mathrm{E} \times \mathrm{V} / \mathrm{C}
$$

(Boudreau 2009; Johns Hopkins and IFRC 2007)

To explain this equation, we will give an example.

The risk (R) that a young child will die from measles is a function of whether or not there is a hazard $(\mathrm{H})$ (the measles virus is present in the population), how exposed (E) the child is to the virus (the severity of infection is influenced by the amount of viral exposure, and this may be increased in crowded conditions). The risk is exacerbated by the vulnerability (V) of the child (e.g. malnutrition), or mitigated by the coping capacity (C) of the child, e.g. due to vaccination. The example of measles is often given, since measles is one of the most contagious diseases known. Measles case fatality ${ }^{4}$ for children in non-conflict settings is less than $1 \%$, while in conflict settings it is up to $30 \%$, for the reasons mentioned above (UNICEF 2016).

A bio-ethically and technically well-founded approach would call for addressing all the contributing factors. In the immediate aftermath of a disaster, a decision might be taken to prioritise vaccination, because it is faster and less expensive than improving nutritional levels. Longer-term, it would be essential to improve the nutritional status, for general health and wellbeing as well as to prevent measles deaths (UNICEF 2016).

Overall, targeted risk reduction strategies, building on lessons from centuries of public health, have resulted in greatly reduced mortality. For example, after the 1991 hurricane in Bangladesh, it was clear that women were dying at higher rates than men. One of the measures taken was to expand the radio system, so that women in their homes could hear about the approaching disaster and seek shelter (Eklund and Tellier 2012).

\footnotetext{
${ }^{4}$ Case fatality: the proportion of persons who die from a disease (number who die divided by the number of diagnosed cases). Most usefully applied to monitor short duration illness, such as measles, as opposed to AIDS or cancer.
} 


\subsubsection{Prioritisation and Efficiency}

As mentioned repeatedly above, prioritisation is a fundamental bio-ethical concern in public health: which health problems are most pressing? Which resources should be used to address them? Which groups should be targeted? This has developed over time.

As mentioned above, the Red Cross in 1864 focussed on group 1 disease - injury in victims of armed conflict. ${ }^{5}$

During the twentieth century, humanitarian response broadened, including civilian victims as well as 'natural disaster'. The priority of PHHA began to shift to Group 1 diseases (communicable, nutritional, maternal conditions). Successive Sphere Manuals have emphasized both risk factors (for example WASH and nutrition) and response (for example outbreak control). Reproductive health was added as a focus area in 1996 (IAWG 2010).

In the last decade, there is a growing interest in Group 2 (non-communicable diseases). In 2008, agreement was reached on an approach for mental health and psycho-social support (IASC 2007). For other non-communicable diseases, the author experienced strong resistance by colleagues, and by medical journals, when she brought it up as a bio-ethical challenge in 2009, with some of the reasons given that it was too expensive or complicated to address. In the last few years, it is increasingly recognized (possibly influenced by the Syrian crisis), but guidelines have still to be fully developed (Demaio et al. 2013).

This gradual shift of focus reflects both the changing baseline burden of disease, as well as changing characteristics of populations affected by disasters.

'Triage' is a basic approach, often used in surgery, but with wider application. It is used to describe how treatment of patients is prioritised. Any prioritisation involves bio-ethical considerations, and these decisions can be difficult, despite the availability of agreed technical standards. For treatment of injury, in cases of 'multiple casualties', which stretch but do not overwhelm the capacity of the health system to respond, the priority may be to serve those in most imminent danger of dying. In cases of 'mass casualties', where the health system is overwhelmed and not able to respond according to 'normal' standards, this prioritization may be turned on its head, with priority placed on serving those who are most likely to survive (Tellier and Roche 2017). As mentioned above, this may be one reason NCDs (Group 2) have only slowly been prioritised, as it is rare they cause massive sudden death, and their treatment is complex and expensive.

${ }^{5}$ Reference is made to the disease groupings given in Sect. $2.3-1,2$ and 3 . 


\subsubsection{Coordination: Health Cluster}

Coordination is a central concern in humanitarian action. Going back to the definition of disasters, the concept is that the affected community or country cannot cope. The question then is, if the national government does not have the capacity to coordinate international humanitarian organizations, who does?

The 1991 46/182 UN General Assembly Resolution for strengthening response to disasters was a milestone, intended to address that problem (UN 1991). It established a UN humanitarian coordinator, as well as an Inter-Agency Standing Committee (IASC), which coordinates approaches and establishes standards and guidelines. After the 1994 Rwanda crisis, the Red Cross/Red Crescent and a group of NGOs united in producing the 'Sphere Project', with a humanitarian charter and minimum standards for humanitarian response (stating that populations affected by disasters have rights).

Another milestone in humanitarian action was in 2005, with the creation of what often is referred to as the IASC 'cluster system'. So far there are 11 clusters at global level, and WHO is the global lead for the health cluster (IASC 2015).

The vision of the cluster is to reduce avoidable mortality, morbidity and disability, and restore the delivery of, and equitable access to, preventive and curative health care as quickly as possible and in as sustainable a manner as possible (IASC 2008). Reviews indicate that the cluster system has resulted in improvements in coordination, with less overlap or gaps (IASC 2015; Olu et al. 2015). They also indicate that for the first decade of implementation the focus has been too much on process and too little on results, and that one of the most difficult areas seems to be coordination with local actors, including handing over to them when humanitarian actors leave (IASC 2015; Olu et al. 2015).

\subsubsection{Preparedness}

As for most humanitarian action, preparedness is essential for PHHA. Many humanitarian actors adopt an 'all-hazards' approach, that is, making preparations which can be applied in the early stages of a wide variety of disasters. They have a blueprint nature, since it is difficult to make plans for all situations. The approach is then phased over time: in principle action is modified, as the situation evolves, better information becomes available, and there is less time pressure (again underscoring the importance of continuing assessment and prioritisation).

For example, the IASC health cluster has developed Interagency Emergency Health Kits, which are stored (in humanitarian jargon: 'pre-positioned') for example in the UNICEF warehouse in Copenhagen. Such kits may be prepared to meet the needs of a standard population: for example 10,000 people for a period of 3 months. The kits are painfully wasteful because they have not been targeted and therefore contain commodities that will never be used. However, when a massive 
emergency occurs and commodities have to be shipped, pre-packaging reduces the reaction time, and increases what is termed 'surge capacity' - that is, the ability to react speedily, massively and, hopefully, meaningfully.

Another example is Emergency Medical Teams (EMTs), until recently named Foreign Medical Teams. A major bio-ethical issue in the past has been that unqualified and ill-equipped health workers have arrived, without procedures for screening them, with inadequate or non-existent equipment and support systems, and potentially causing more harm than good. A certification process, including detailed technical standards and a classification system, was introduced by WHO in 2013. EMTs are expected to come as a team, have quality training, as well as equipment/supplies in order to successfully respond rather than be a burden on the national system. The lead of the health cluster at country level is expected to help local authorities check those qualifications (Norton et al. 2013).

A recent review finds a continuing competence gap - well-established EMTs keep improving, but unprepared and poorly equipped teams continue to arrive, overwhelming affected countries. Deployment to date has concentrated on surgical teams, which are expensive and may not correspond to main needs. Another issue is a need for better legal and procedural preparedness at the national level to facilitate the entry and coordination of the EMTs (WHO 2017).

\subsubsection{Building on Local Systems and Exit Strategy}

The concepts and norms are clear: international humanitarian action in disasters is informed by the understanding that the affected community temporarily 'cannot cope'.

Equally important is the understanding that the role of any outsiders is to plan their action in a manner that at least does not weaken local structures, but supplements and ideally strengthens local capacity. For the health field, this means building on the local health system, and that can be particularly complex. One key feature of health systems is that they have a method of referring complicated cases from the simplest, primary level (e.g. a local clinic) to a higher, more sophisticated level (e.g. a 'tertiary' hospital). All levels must function at the same time, making them different from, for example, educational systems (IASC 2008; IFRC 1996; UN 1991; UNISDR 2005). This makes harmonisation even more challenging.

IASC guidelines on health recovery emphasize that programming for development needs to begin at the earliest possible stage of relief work (IASC 2008). The guidelines suggest using the six building blocks of health systems (see above under Sect. 4.1) as an analytical framework for situation analysis and response planning. Lessons are becoming clearer on do's and don'ts. 
For example:

- Governance: in emergency situations, a segmented approach is often adopted, depending on access to unsafe areas, areas controlled by different groupings or different approaches by different international actors. This makes it more difficult to establish a national plan, functioning at all the levels mentioned above, as in Afghanistan (Newbrander et al. 2014)

- However, disasters can also be opportunities for management reform (Boin et al. 2005). A study by Nyenswah et al. from Liberia describes how governmental structures were made more effective in the Ebola crisis, as those workers who did not perform were dismissed, whereas those who remained were able to build leaner, flatter decision-making structures (Nyenswah et al. 2016). The main concern identified by the article is that the system will revert to old habits one the emergency is over.

- Human resources: in Cambodia internationals trained 59 different categories of health workers, which met their immediate needs but did not correspond to local standards of qualifications and therefore could not be integrated into the national system when internationals left (Nabarro and Evans 2005). A frequent problem is that internationals pay salaries are not sustainable by local organizations.

- Service delivery: in Afghanistan a basic package of health services (BPHS) was developed, based on the above-mentioned six building blocks of health systems. It was budgeted at a low cost, with funding committed by three major donors, yet faced challenges in implementation (Edward et al. 2011; Health and Fragile States Network 2009; Newbrander et al. 2014).

- Vaccines and medicines: essential drugs programmes can be easier to introduce in countries where there is no well-established commercial drug industry (IASC 2008).

\subsubsection{An Example of Sectoral Guidelines}

One key role of the IASC is to develop norms in the form of technical guidelines, to encourage better quality and coordination. Here we will give one illustrative example: reproductive health. The IASC sets out a minimum initial service package (MISP) to be implemented in the first 3 months after a disaster strikes, before it may have been possible to do a detailed situation assessment:

1. Identify a coordinator

2. Initiate action to prevent avoidable maternal and neonatal mortality

3. Prevent and treat HIV/AIDS

4. Prevent and treat gender based violence

5. Plan for integration into local services, to allow for a broader approach 
This reflects the bio-ethical principles mentioned above: strict prioritisation of life-saving interventions, acknowledgement that action may be taken even without full assessment, acknowledging the importance of coordination, and the beginnings of an exit strategy. Health kits have been developed to support the indicated activities (IAWG 2010).

\subsection{Personal Reflections: Some Bio-ethical Challenges and Dilemmas}

Public health has strong, strikingly clear and consistent bio-ethical values, with the utilitarian goal of improving health as much as possible for as many people as possible. These values hold, sometimes in exacerbated form, in humanitarian situations. But many dilemmas occur.

1. Prioritisation: prioritisation (including triage) is at the heart of public health action. Prioritising one activity necessarily means deprioritising another. The bio-ethical choice can be excruciatingly difficult to make, professionally, politically and personally. Professional decisions can be difficult, but the political perception of that choice, by populations and authorities, can be even more so. If one population group is more at risk than another, and humanitarians prioritise interventions for that group, this may cause political problems. A choice not to give antibiotics to a population struck by cholera may be perceived as giving treatment which is second best, even though technical evidence shows it is as effective as the lower cost Oral Rehydration Therapy. Many professionals have informed me that their most recurrent nightmares were remembering the patients they had to deprioritize for lack of capacity.

2. Business continuity: people continue to have health problems not associated with the disaster, for example traffic accidents or obstetric emergencies. Yet, the local health system may have been incapacitated, meaning it cannot maintain business continuity. Funding for humanitarian action does not always provide for treating health problems not associated with the disaster, and local laws or organizational guidelines may disallow it. Should humanitarians treat them nevertheless? What if donors do not allow it?

3. Standards: health is a comparatively regulated field, and most countries have standards for protected medical professions and treatments. Health humanitarians also have an ever-expanding set of standards. However, not all countries live up to those standards, and humanitarians do not always follow them if they find them inappropriate. In the case of controversial issues such as abortion, national laws may be at direct odds with personal or organisational bio-medical ethics and professional standards (for example, five countries do not allow abortion even to save the life of the mother). One large donor variously permits, or does not permit, funding of organisations which treat or refer patients for abortion, including where national laws permit it.

4. Exit Strategy: the IASC guidelines for health recovery propose that services and staff training should be in accordance with the six building blocks of the local 
health system in order to facilitate post-emergency handover to local institutions. However, in an emergency, if you need to make rapid decisions about prioritisation, e.g. measles vaccination, there may not be time to train staff, say, in the full job description of a community health worker. In the Haiti earthquake, the policy before the 2010 earthquake was based on fee-for-service. During the disaster, it is difficult for an emergency surgical team to ask for payment. However, it made the post-disaster return to the national policy more difficult (PAHO 2011)

5. Access/security: health humanitarians are faced with the same problems as other humanitarians: they may not be able to access the groups which need them the most. There seem to be increasing numbers of targeted attacks on local and international health providers. It is an eternal dilemma to decide under which conditions services should be continued.

6. Coordination: humanitarian actors sometimes are criticised for acting in a chaotic manner, or not planning for the longer term. The solution is sometimes seen as developing more guidelines and policies to improve coordination, technical quality and planning. For example, there is an exhortation for community participation, 'localisation' (channelling funding as directly as possible to local organisations), yet this may pose bio-ethical dilemmas in living up to principles of neutrality and impartiality (Brown and Donini 2015; Cohn and Kutalek 2016; duBois 2016; Schenkenberg 2016). Humanitarian work is riddled with dilemmas, but as one observer notes, the dilemmas that humanitarian workers experience cannot be remedied by declaring ever-expanding sets of principles to dictate practice (Hilhorst and Jansen 2013; Valbak 2016). This author would suggest better analysis of why bio-ethical principles and guidelines are not followed, rather than producing more guidelines. Possibly that is more difficult - guidelines are something authorities can delegate to staff, whereas analysis of why they are not followed may identify issues where authorities themselves need to change.

7. Funding: this relates to the omnipresent issue of funding -perhaps the most pressing problem. Humanitarian action is often based on raising funding after action has begun. All the above dilemmas and ethical choices are deeply dependent on funding decisions, many of which may be unpredictable and incomprehensible for field workers.

The former Emergency Relief Coordinator, Jan Egeland, sometimes quoted a famous aphorism: We try, we fail. We try again, we fail better.

Or, in another medium:

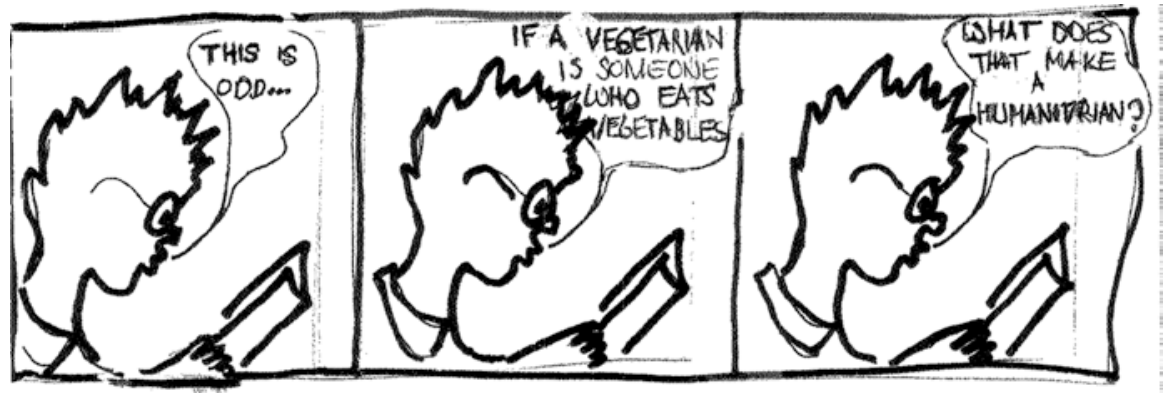




\section{References}

Adams, V., S.R. Kaufman, T. van Hattum, and S. Moody. 2011. Aging disaster: Mortality, vulnerability, and long-term recovery among Katrina survivors. Medical Anthropology 30 (3): 247-270. https://doi.org/10.1080/01459740.2011.560777.

Baker, M.G., and D.P. Fidler. 2006. Global public health surveillance under new international health regulations. Emerging Infectious Diseases 12 (7): 1058-1065. https://doi.org/10.3201/ eid1207.051497.

Boin, A., P. Hart, E. Stern, B. Sundelius, and M. Inambao. 2005. The politics of crisis management. Cambridge, UK: Cambridge University Press.

Boudreau, Tanya. 2009. Solving the risk equation people-centred disaster risk assessment in Ethiopia. Humanitarian Practice Network Network Paper. http://odihpn.org/wp-content/ uploads/2009/06/networkpaper066.pdf. Accessed 16 Apr 2018.

Brody, H., M.R. Rip, P. Vinten-Johansen, N. Paneth, and S. Rachman. 2000. Map-making and myth-making in Broad Street: The London cholera epidemic, 1854. Lancet 356 (9223): 64-68. https://doi.org/10.1016/S0140-6736(00)02442-9.

Brown, Dayna, and Donini, Antonio. 2015. Rhetoric or reality? Putting affected people at the centre of humanitarian action. ALNAP Study. http://www.alnap.org/resource/12859. Accessed 16 Apr 2018.

Burnham, G., R. Lafta, S. Doocy, and L. Roberts. 2006. Mortality after the 2003 invasion of Iraq: A cross-sectional cluster sample survey. Lancet 368 (9545): 1421-1428. https://doi.org/10.1016/ S0140-6736(06)69491-9.

Cash, Richard A., Gerald Keusch, and Joel Lamstein. 1987. Child health and survival: The UNICEF Gobi-FFF program. London: Room Helm.

Christensen, K., G. Doblhammer, R. Rau, and J.W. Vaupel. 2009. Ageing populations: The challenges ahead. Lancet 374 (9696): 1196-1208. https://doi.org/10.1016/S0140-6736(09)61460-4.

Cohn, S., and R. Kutalek. 2016. Historical parallels, ebola virus disease and cholera: Understanding community distrust and social violence with epidemics. PLOS Currents Outbreaks 8. doi:https://doi.org/10.1371/currents.outbreaks.aa1f2b60e8d43939b43fbd93e1a63a94.

CRED. 2013. People affected by conflict 2013 - humanitarian needs in numbers. CRED. http:// reliefweb.int/sites/reliefweb.int/files/resources/PubID303ConflictReport.pdf. Accessed 16 Apr 2018.

- Frequently asked questions. http://www.emdat.be/frequently-asked-questions. Accessed 16 Apr 2018.

Demaio, A., J. Jamieson, R. Horn, M. de Courten, and S. Tellier. 2013. Non-communicable diseases in emergencies: a call to action. PLoS Currents 6: 5. https://doi.org/10.1371/currents.dis $.53 \mathrm{e} 08 \mathrm{~b} 951 \mathrm{~d} 59 \mathrm{ff} 913 \mathrm{ab} 8 \mathrm{~b} 9 \mathrm{bb} 51 \mathrm{c} 4 \mathrm{~d} 0 \mathrm{de}$.

duBois, Marc. 2016. Be careful what you wish for - will local NGOs fall into the same trap as their northern cousins? World Humanitarian Summit 2016: 20160808.

duBois, Marc, Wake, Caitlin, and with Sturridge, Scarlett, and Bennett, Christina. 2015. The ebola response in West Africa exposing the politics and culture of international aid. HPG Working Paper. https://www.odi.org/sites/odi.org.uk/files/odi-assets/publications-opinion-files/9903. pdf. Accessed 16 Apr 2018.

Edward, A., B. Kumar, F. Kakar, A.S. Salehi, G. Burnham, and D.H. Peters. 2011. Configuring balanced scorecards for measuring health system performance: evidence from 5 years' evaluation in Afghanistan. PLoS Medicine 8 (7): e1001066. https://doi.org/10.1371/journal. pmed.1001066.

Eklund, Lisa, and Siri Tellier. 2012. Gender and international crisis response: Do we have the data, and does it matter? Disasters. https://doi.org/10.1111/j.1467-7717.2012.01276.x.

Ersoy, Nermin, Gungor, Yuksel, and Akpinar, Aslihan. 2011. International sanitary conferences from the Ottoman perspective (1851-1938).

Fenner, Frank. 1988. Development of the global smallpox eradication programme. Smallpox and its eradication In History of international public health, No. 6, 366-418. Geneva: WHO. 
Foege, William H., J.D. Millar, and D.A. Henderson. 1975. Smallpox eradication in West and Central Africa. Bulletin of the World Health Organization 52 (2): 209-222. NA (Bulletin only began attributing DOIs in 2006).

Global Burden of Disease 2015 Mortality and Causes of Death Collaborators. 2016. Global, regional, and national life expectancy, all-cause mortality, and cause-specific mortality for 249 causes of death, 1980-2015: A systematic analysis for the Global Burden of Disease Study 2015. Lancet 388 (10053): 1459-1544. https://doi.org/10.1016/S0140-6736(16)31012-1.

Global Burden of Disease Study 2013 Collaborators. 2015. Global, regional, and national incidence, prevalence, and years lived with disability for 301 acute and chronic diseases and injuries in 188 countries, 1990-2013: A systematic analysis for the Global Burden of Disease Study 2013. Lancet 388: 1545-1602. https://doi.org/10.1016/S0140-6736(15)60692-4.

Health and Fragile States Network. 2009. Health systems strengthening in fragile contexts: A report on good practices and new approaches. London. http://gsdrc.org/document-library/healthsystems-strengthening-in-fragile-contexts-a-report-on-good-practices-and-new-approaches/. Accessed 16 Apr 2018.

Hilhorst, Dorothea, and Bram J. Jansen. 2013. Humanitarian space as arena: A perspective on the everyday politics of aid. Development and Change 41: 1117-1139. https://doi. org/10.1111/j.1467-7660.2010.01673.x.

Hopkins, Johns, Bloomberg School of Public Health, and IFRC. 2007. The Johns Hopkins and Red Cross red crescent public health guide in emergencies. Vol. 2. Geneva: International Federation of Red Cross and Red Crescent Societies.

Howard-Jones, Norman. 1975. The scientific background of the international sanitary conferences (1851-1938). Geneva. Electronic document, Accessed.

IASC. 2007. IASC guidelines for mental health and psycho-social support in emergencies. http:// www.who.int/hac/network/interagency/news/iasc_guidelines_mental_health_psychososial. pdf?ua=1. Accessed 16 Apr 2018.

2008. Health cluster guidance note on health recovery. http://www.who.int/hac/global_ health_cluster/guide/117_iasc_global_health_cluster_recovery_strategy_guidelines.pdf. Accessed 16 Apr 2018.

- 2015. Reference module for cluster coordination at country level. http://who.int/healthcluster/about/cluster-system/cluster-coordination-reference-module-2015.pdf. Accessed 16 Apr 2018.

IAWG, Inter-agency Working Group on Reproductive Health in Crises. 2010. Inter-agency field manual on reproductive health in humanitarian settings - 2010 revision for field review. Geneva: United Nations. http://www.who.int/reproductivehealth/publications/emergencies/ field_manual_rh_humanitarian_settings.pdf. Accessed 16 Apr 2018.

IFRC. 1996. Key factors for developmental relief. International Review of the Red Cross. Geneva. http://www.icrc.org/eng/resources/documents/article/other/57jmvw.htm. Accessed $16 \mathrm{Apr}$ 2018.

Knox, Clarke Paul, and Campbell, Leah. 2015. Exploring coordination in humanitarian clusters. https://reliefweb.int/sites/reliefweb.int/files/resources/study-coordination-humanitarian-clusters-alnap-2015.pdf. Accessed 16 Apr 2018.

Koplan, Jeffrey P., T. Christopher Bond, Michael H. Merson, K. Srinath Reddy, Mario Henry Rodriguez, Nelson K. Sewankambo, and Judith N. Wasserheit. 2009. Towards a common definition of global health. The Lancet 373 (9679): 1993-1995. https://doi.org/10.1016/ S0140-6736(09)60332-9.

McKeown, T., and R.G. Brown. 1955. Medical evidence related to English population changes in the eighteenth century. Population Studies 9: 119-141. https://doi.org/10.2307/2172162.

MSF. 1997. Refugee health: an approach to emergency situations. London: Macmillan.

Murray, C.J., A.D. Lopez, and D.T. Jamison. 1994. The global burden of disease in 1990: summary results, sensitivity analysis and future directions. Bulletin of the World Health Organization 72 (3): 495-509. 
Nabarro, David, and T. Evans. 2005. Guide to health work force development in post-conflict environments. Geneva: World Health Organization. http://apps.who.int/iris/bitstream/handle/10665/43243/9241593288_eng.pdf;jsessionid=BA0246B50164AF0731A674BE8EEA7E 4C? sequence $=1$. Accessed 16 Apr 2018.

Newbrander, W., P. Ickx, F. Feroz, and H. Stanekzai. 2014. Afghanistan's basic package of health services: its development and effects on rebuilding the health system. Global Public Health 9 (Suppl 1):S6-S28. https://doi.org/10.1080/17441692.2014.916735.

Norton, I., J. von Schreeb, P. Aitken, P. Herard, and C. Lajolo. 2013. Classification and minimum standards for foreign medical teams in sudden onset disasters. Health Cluster. Geneva: WHO. http://www.who.int/hac/global_health_cluster/fmt_guidelines_september2013.pdf?ua=1 . Accessed 16 Apr 2018.

Nyenswah, Tolbert, Cyrus Y. Engineer, and David H. Peters. 2016. Leadership in times of crisis: The example of ebola virus disease in liberia. Health Systems \& Reform 2 (3): 194. https://doi. org/10.1080/23288604.2016.1222793.

Ó Gráda, Cormac. 2009. Famine - a short history. Princeton/Oxford: Princeton University Press.

Olu, O., A. Usman, S. Woldetsadik, D. Chamla, and O. Walker. 2015. Lessons learnt from coordinating emergency health response during humanitarian crises: A case study of implementation of the health cluster in northern Uganda. Conflict and Health 9: 1. https://doi. org/10.1186/1752-1505-9-1.

Omran, A.R. 1971. The epidemiologic transition. A theory of the epidemiology of population change. Milbank Memorial Fund Quarterly 49 (4): 509-538. https://doi.org/10.111 1/j.1468-0009.2005.00398.

PAHO. 2011. Health response to the earthquake in Haiti, January 2010 - lessons to be learned for the next massive sudden-onset disaster. Washington, DC: Pan American Health Organization. http://reliefweb.int/sites/reliefweb.int/files/resources/Full_Report_3342.pdf. Accessed 16 Apr 2018.

Parham, Nic (ACAPS). 2016. Flying blind? Gathering and using quality information in situations of constrained access. Third webinar of the ALNAP Bridgoin the evidence gap series. Online event (webinar), ALNAP.

Price, Megan, Gohdes, Anita, and Ball, Patrick. 2014. Updated statistical analysis of documentation of killings in the Syrian Arab Republic. UNHCR. http://www.ohchr.org/Documents/ Countries/SY/HRDAGUpdatedReportAug2014.pdf. Accessed 16 Apr 2018.

Rabkin, M., F.M. Fouad, and W.M. El-Sadr. 2016. Addressing chronic diseases in protracted emergencies: Lessons from HIV for a new health imperative. Global Public Health 1-7. doi:https:// doi.org/10.1080/17441692.2016.1176226.

Riley, James C. 2005. Estimates of regional and global life expectancy, 1800-2001. Population and Development Review 31 (3): 537-543. https://doi.org/10.1111/j.1728-4457.2005.00083.x.

Ruby, Alexander, Abigail Knight, Pablo Perel, Karl Blanchet, and Bayard Roberts. 2015. The effectiveness of interventions for non-communicable diseases in humanitarian crises: A systematic review. PLoS One 10 (9): e0138303. https://doi.org/10.1371/journal.pone.0138303.

Schenkenberg, E. 2016. Emergency gap: The challenges of localised humanitarian aid in armed conflict. Médecins Sans Frontières. https://arhp.msf.es/sites/default/files/MSF_EGS03_ The $\% 20$ challenges $\% 20$ of $\% 20$ localised $\% 20$ humanitarian $\% 20$ aid $\% 20$ in $\% 20$ armed $\% 20$ conflict_november\%202016_0_0.pdf. Accessed 16 Apr 2018.

Sphere Project. 2004 Humanitarian charter and minimum standards for disaster response. Geneva: The Sphere Project. http://ocw.jhsph.edu/courses/RefugeeHealthCare/PDFs/ SphereProjectHandbook.pdf. Accessed 16 Apr 2018.

— 2011 The sphere handbook: Humanitarian charter and minimum standards for disaster response. Geneva: The Sphere Project. http://www.ifrc.org/PageFiles/95530/The-SphereProject-Handbook-20111.pdf Accessed 16 Apr 2018.

Spiegel, P.B., F. Checchi, S. Colombo, and E. Paik. 2010. Health-care needs of people affected by conflict: future trends and changing frameworks. Lancet 375 (9711): 341-345. https://doi. org/10.1016/S0140-6736(09)61873-0. 
Sriram, C.L., C.J. King, Julie A. Mertus, Olga Martin-Ortega, and Johanna Herman. 2009. Surviving field research: Working in violent and difficult situations. London: Routledge.

Tapp, C., F.M. Burkle Jr., K. Wilson, T. Takaro, G.H. Guyatt, H. Amad, and E.J. Mills. 2008. Iraq war mortality estimates: A systematic review. Conflict and Health 2: 1. https://doi. org/10.1186/1752-1505-2-1.

Taubenberger, J.K., and D.M. Morens. 2006. 1918 Influenza: The mother of all pandemics. Emerging Infectious Diseases 12 (1): 15-22. https://doi.org/10.3201/eid1201.050979.

Tellier, Siri. 2014. Technical brief: Demographic profile using secondary data. Geneva: ACAPS. https://www.acaps.org/sites/acaps/files/resources/files/demographic_profile_using_secondary_data_august_2014.pdf. Accessed 16 Apr 2018.

Tellier, Siri, and Roche, Niall (eds). 2017. Basic concepts and current challenges of public health in humanitarian action. In International humanitarian action, ed. H.-J. Heitze and P. Thielbörger, 229-320. Springer.

Toole, M.J., and R.J. Waldman. 1990. Prevention of excess mortality in refugee and displaced populations in developing countries. The Journal of the American Medical Association 263 (24): 3296-3302. https://doi.org/10.1001/jama.1990.03440240086021.

UN. 1948. Universal declaration of human rights, United Nations General Assembly in Paris on 10 December 1948 (General Assembly resolution 217 A).

- 2015. The millennium development goals report 2015. New York: United Nations. http://www.un.org/millenniumgoals/2015_MDG_Report/pdf/MDG\%202015\%20rev\%20 (July\%201).pdf. Accessed 16 Apr 2018.

UN, Committee on Economic, Social and Cultural Rights. 2000. General comment no. 14, the right to the highest attainable standard of health (article 12 of the international covenant on economic, social and cultural rights). http://tbinternet.ohchr.org/_layouts/treatybodyexternal/ Download.aspx?symbolno=E\%2fC.12\%2f2000\%2f4\&Lang=en. Accessed 16 Apr 2018.

UN, Department of Economic and Social Affairs, Population Division. 2014. World urbanization prospects: The 2013 revision, highlights. New York: UN, Department of Economic and Social Affairs, Population Division. http://esa.un.org/unpd/wup/. Accessed 16 Apr 2018.

UN, General Assembly 78th Plenary meeting. 1991. Strengthening of the coordination of humanitarian emergency assistance of the United Nations, A/RES/46/182. General Assembly, 78th Plenary meeting. http://www.un.org/documents/ga/res/46/a46r182.htm. Accessed 16 Apr 2018.

UNHCR. 2018. Emergency handbook. Geneva: UNHCR. https://emergency.unhcr.org/ entry/86022/acute-malnutrition-threshold. Accessed 16 Apr 2018.

UNICEF. 2016. Two-thirds of unimmunized children live in conflict-affected countries. Press release, 24-30 Apr 2016.

UNISDR. 2005. Hyogo framework for action 2005-2015: Building the resilience of nations and communities to disasters. United Nations. http://www.unisdr.org/files/1037_hyogoframeworkforactionenglish.pdf. Accessed 16 Apr 2018.

—. 2016. Terminology: Disaster. https://www.unisdr.org/we/inform/terminology\#letter-d. Accessed 26 Apr 2018.

United Nations, Department of Economic and Social Affairs Population Division. 2017. World population prospects: The 2017 revision. New York: United Nations. http://esa.un.org/unpd/ wpp/. Accessed 16 Apr 2018.

Valbak, Iben Gejl. 2016. The everyday practices of aid: A phenomenological analysis of international humanitarian aid workers' experiences of collaborating with Nepalese government officials following the Nepal earthquake 2015. University of Copenhagen.

Virchow, Rudolf. 1848. Die Medizinische reform. In 1941, medicine and human welfare, Henry Ernest Sigerist. New Haven: Yale University Press.

WHO. 1946. Preamble to the constitution of the world health organization as adopted by the international health conference. New York, 19-22 June, 1946; signed on 22 July 1946 by the representatives of 61 States (Official Records of the World Health Organization, no. 2, p. 100) and entered into force on 7 April 1948. New York. 
1978. Declaration of Alma-Ata. International Conference on Primary Health Care, AlmaAta, 6-12 September 1978, USSR, 1978.

. 2007. Everybody's business: Strengthening health systems to improve health outcomes. WHO's framework for action. Geneva: WHO. http://www.who.int/healthsystems/strategy/ everybodys_business.pdf. Accessed 16 Apr 2018.

—. 2008. International health regulations 2005. http://apps.who.int/iris/bitstream/han dle/10665/246107/9789241580496-eng.pdf?sequence=1. Accessed 16 Apr 2018.

. 2014. What is universal health coverage? http://www.who.int/features/qa/universal_ health_coverage/en/. Accessed 20170115. Accessed 15.012017.

. Glossary - public health. http://www.who.int/healthsystems/hss_glossary/en/index8. html. Accessed 16 Apr 2018.

WHO, Commission on Macroeconomics and Health. 2001. Macroeconomics and health: Investing in health for economic development. http://apps.who.int/iris/bitstream/ handle/10665/42435/924154550X.pdf?sequence=1\&isAllowed=y. Accessed 16 Apr 2018.

WHO, IFRC. 2017. The regulation and management of international emergency medical teams. http://www.ifrc.org/PageFiles/115542/EMT\%20Report\%20HR.PDF. Accessed 16 Apr 2018.

World Bank. 1993. World development report 1993: Investing in health. New York: Oxford University Press. https://openknowledge.worldbank.org/handle/10986/5976. Accessed 16 Apr 2018.

Indicators. https://data.worldbank.org/indicator/. Accessed 16 Apr 2018.

Open Access This chapter is licensed under the terms of the Creative Commons Attribution 4.0 International License (http://creativecommons.org/licenses/by/4.0/), which permits use, sharing, adaptation, distribution and reproduction in any medium or format, as long as you give appropriate credit to the original author(s) and the source, provide a link to the Creative Commons license and indicate if changes were made.

The images or other third party material in this chapter are included in the chapter's Creative Commons license, unless indicated otherwise in a credit line to the material. If material is not included in the chapter's Creative Commons license and your intended use is not permitted by statutory regulation or exceeds the permitted use, you will need to obtain permission directly from the copyright holder.

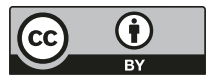

